Article

\title{
Sulpho-Salicylic Acid Grafted to Ferrite Nanoparticles for n-Type Organic Semiconductors
}

\author{
Cristian Ravariu ${ }^{1, *(\mathbb{D})}$, Dan Mihaiescu ${ }^{2}$, Alina Morosan ${ }^{2}$, Bogdan Stefan Vasile ${ }^{3}(\mathbb{D}$ and \\ Bogdan Purcareanu ${ }^{4}$ \\ 1 Department of Electronic Devices Circuits \& Architectures, Faculty of Electronics Telecommunications and \\ Information Technology, Polytechnic University of Bucharest, S6 060042 Bucharest, Romania \\ 2 Department of Organic Chemistry "Costin Nenitescu”, Faculty of Applied Chemistry and Materials Science, \\ Politehnica University of Bucharest, S1 011061 Bucharest, Romania; dan.mihaiescu@upb.ro (D.M.); \\ alina.morosan@upb.ro (A.M.) \\ 3 Department of Engineering of Oxide Materials and Nanomaterials, Faculty of Applied Chemistry and \\ Materials Science, Politehnica University of Bucharest, S1 011061 Bucharest, Romania; bogdan.vasile@upb.ro \\ 4 S.C. Biotehnos S.A., Gorunului Street 3, 075100 Otopeni, Romania; bogdan.purcareanu@upb.ro \\ * Correspondence: cristian.ravariu@upb.ro
}

Received: 31 August 2020; Accepted: 7 September 2020; Published: 9 September 2020

\begin{abstract}
A disadvantage of the use of pentacene and typical organic materials in electronics is that their precursors are toxic for manufacturers and the environment. To the best of our knowledge, this is the first report of an n-type non-toxic semiconductor for organic transistors that uses sulpho-salicylic acid - a stable, electron-donating compound with reduced toxicity-grafted on a ferrite core-shell and a green synthesis method. The micro-physical characterization indicated a good dispersion stability and homogeneity of the obtained nanofilms using the dip-coating technique. The in-situ electrical characterization was based on a point-contact transistor configuration, and the increase in the drain current as the positive gate voltage increased proved the functionality of the n-type semiconductor.
\end{abstract}

Keywords: nanocore; organic shell; green semiconductors; n-type film

\section{Introduction}

The latest advances in materials science successfully serve nanoelectronics' interests, such as flexible electronic devices with elastomeric substrates [1], field-effect transistors attached to a gold electrode sensing pad for deoxyribonucleic acid hybridization [2], carbon-related materials such as diamond [3], or nanocomposites serving as efficient hole-transporting layers for organic solar cells [4]. Additionally, organic materials have been improved over the last 20 years, and now present superior performance than inorganic materials for thin-film transistors (TFTs) [5]. A convenient method for the deposition of organic materials is dip-coating, as reported in 2019 by other authors for metal-organic frameworks [6]. This method works at room temperature and it is suitable for the deposition of $100 \mathrm{~nm}$ organic layers. Polymers with small molecules, such as pentacene, are the most widely used organic semiconductors for p-type materials nowadays [7], as well as for n-type materials under special conditions [8]. The precursors of pentacene are polycyclic aromatic hydrocarbons (PAHs), and their toxicity comes from the ability of these PAHs to bind to deoxyribonucleic acid inside cells, thereby producing disruptive effects [9]. Therefore, the green technologies are much sought after for solar cells [10] and other electronic devices [11]. During an international forum in 2018, the future technology of the third generation of organic light-emitting diodes (OLEDs) for display purposes was eco-friendly defined in terms of low power consumption and long lifetime [12]. However, after carrying out a search, zero results were returned for green technologies for n-type organic transistors, except one regarding green solvents [13]. 
This work was intended to enlarge the gates toward green organic technologies at room temperature, searching for new types of semiconductors with low toxicity and simple molecular organization. In our previous studies, para-aminobenzoic acid was used to construct a p-type green semiconductor [14]. A non-toxic organic compound, acting as an electron donor, is sulpho-salicylic acid (SSA), the chemical structure of which is presented in Figure 1. SSA can be efficiently attached to the external shell of a ferrite $\left(\mathrm{Fe}_{3} \mathrm{O}_{4}\right)$ nanocore, providing $\mathrm{Fe}_{3} \mathrm{O}_{4}$-SSA nanoparticles using self-assembling techniques [15]. Essentially, an $\mathrm{Fe}_{3} \mathrm{O}_{4}$ nanocore represents an intrinsic semiconductor and SSA is suitable for organic electronic devices due to its molecular conjugation [16]. The self-assembly of SSA onto the external shell of ferrite nanoparticles easily occurs during the synthesis step, yielding core-shell nanoparticles with a good dispersibility in water. To create a demonstrator, we used a low-cost technology to deposit $\mathrm{Fe}_{3} \mathrm{O}_{4}$-SSA onto a compatible insulator on indium tin oxide (ITO)-coated glass. Finally, we tested the n-type characteristics of the $\mathrm{Fe}_{3} \mathrm{O}_{4}-\mathrm{SSA}$ film using a point-contact transistor. The $\mathrm{Fe}_{3} \mathrm{O}_{4}$-SSA film was contacted by two probes, i.e., the source and drain, and the ITO film was contacted by a third probe, i.e., the gate. This point-contact transistor, also named pseudo-MOS (Metal Oxide Semiconductor) or $\Psi$-MOSFET (Metal Oxide Semiconductor Field Effect Transistor) transistor, is specifically used for the in-situ electrical characterization of the conduction in thin semiconductors on insulators $[17,18]$, including organic biomaterials $[19,20]$. The next paragraph presents the synthesis and microphysical characterization of $\mathrm{Fe}_{3} \mathrm{O}_{4}-\mathrm{SSA}$.<smiles>O=C(O)c1cc(S(=O)(=O)O)ccc1O</smiles>

Figure 1. The chemical structure of sulpho-salicylic acid (SSA).

\section{2. $\mathrm{Fe}_{3} \mathrm{O}_{4}-\mathrm{SSA}$ Synthesis and Characterization}

For the synthesis of the $\mathrm{Fe}_{3} \mathrm{O}_{4}$-SSA nanoparticles, the following substances were acquired from Sigma-Aldrich (Redox Lab Supplies Com S.R.L., Bucharest, Romania): Ferric chloride ( $\mathrm{FeCl}_{3}$ ), ferrous sulphate heptahydrate $\left(\mathrm{FeSO}_{4} \cdot 7 \mathrm{H}_{2} \mathrm{O}\right)$, sodium hydroxide $(\mathrm{NaOH})$, and sulpho-salicylic acid (SSA). During all washing steps, high-purity water of $18.2 \mathrm{M} \Omega \cdot \mathrm{cm}$ was used. The nanoparticles were prepared from primary ferrite nanocore particles $\left(\mathrm{Fe}_{3} \mathrm{O}_{4}\right)$ by a modified co-precipitation technique, described in detail in [21]. A $2.5 \mathrm{~g} \mathrm{Fe}^{2+} / \mathrm{Fe}^{3+}$ stoichiometric mixture from iron sulphate and iron chloride, in $400 \mathrm{~mL}$ $\mathrm{H}_{2} \mathrm{O}$, was used as the magnetite precursor, and co-precipitation was performed using a $7 \mathrm{~g} \mathrm{NaOH}$ and $3 \mathrm{~g}$ SSA in $400 \mathrm{~mL} \mathrm{H}_{2} \mathrm{O}$ solution under continuous stirring.

The final aqueous solution with dispersed $\mathrm{Fe}_{3} \mathrm{O}_{4}-\mathrm{SSA}$ nanoparticles was microphysically characterized by Fourier transform infrared spectroscopy (FT-IR: Thermo Nicolet 6700 spectrometer, Thermo Fisher Scientific, Waltham, MA, USA), dynamic light scattering (DLS: Zetasizer Nano ZS, Malvern Instruments, Malvern, UK), and transmission electron microscopy (TEM: Carl Zeiss, Oberkochen, Germany). FT-IR spectra were recorded using a ZnSe window H-ATR (Horizontal Attenuated Total Reflectance) mounted on a Thermo Nicolet 6700 spectrometer (Figure 2). The FT-IR spectra of the $\mathrm{Fe}_{3} \mathrm{O}_{4}$-SSA nanoparticles presented a characteristic band assigned to the $\mathrm{Fe}-\mathrm{O}$ stretching at $556 \mathrm{~cm}^{-1}$. The existence of an SSA shell was confirmed by the presence of a characteristic absorption band for the asymmetric stretching vibrations of the carboxylate groups at $1556 \mathrm{~cm}^{-1}$, the symmetric stretching vibrations of the sulphonate groups at 1023 and $1160 \mathrm{~cm}^{-1}$, and the asymmetric stretching vibrations of the sulphonate groups at $1338 \mathrm{~cm}^{-1}$. 


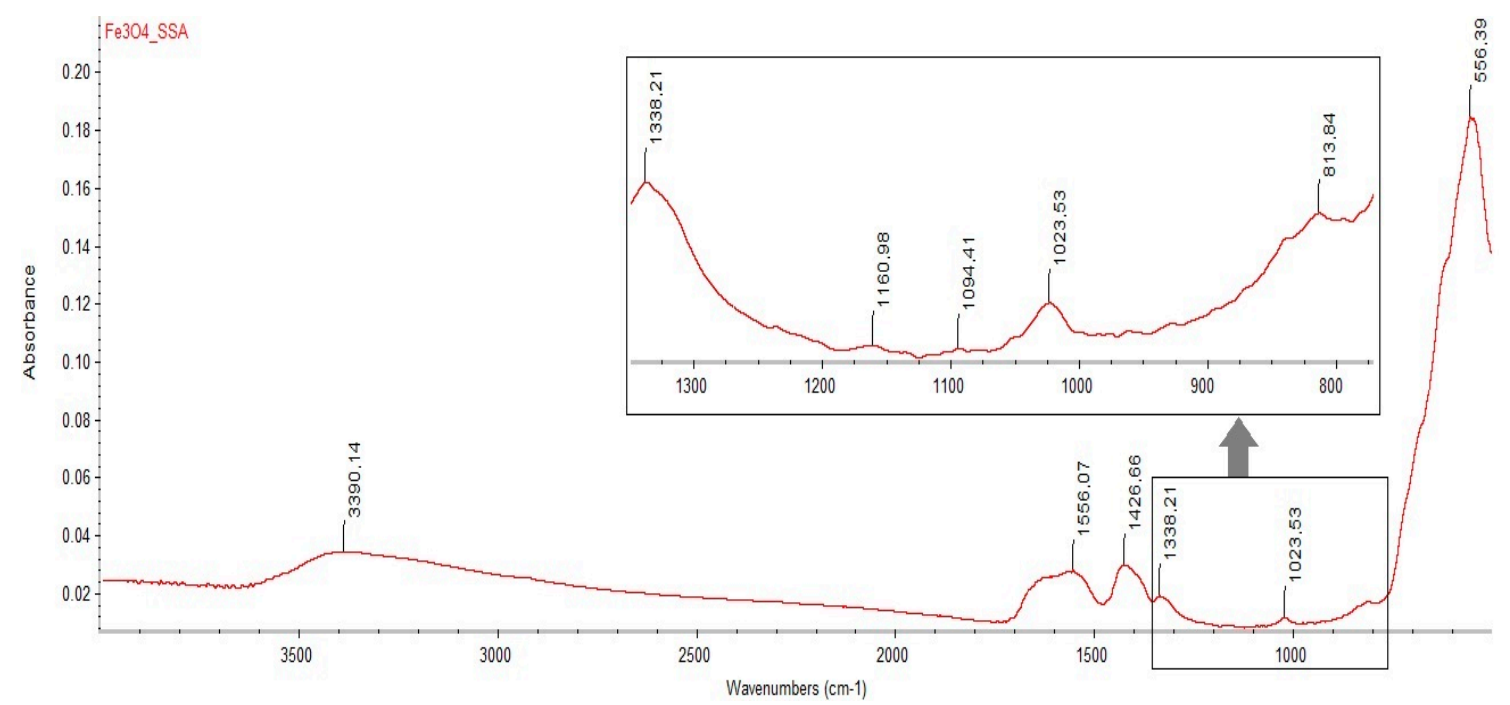

Figure 2. The measured Fourier transform infrared spectroscopy (FT-IR) spectrum of the $\mathrm{Fe}_{3} \mathrm{O}_{4}-\mathrm{SSA}$ nanoparticles for wavenumbers from 4000 to $500 \mathrm{~cm}^{-1}$. The inset provides a detailed overview of wavenumbers between 1338.21 and $813.84 \mathrm{~cm}^{-1}$.

The skeletal vibration of benzene ring bonds is evidenced by the presence of a characteristic band at $1426 \mathrm{~cm}^{-1}$ in the FT-IR spectra. The band around $1094 \mathrm{~cm}^{-1}$ is assigned to the symmetric stretching vibration of a $\mathrm{C}-\mathrm{C}$ bond between the aromatic ring and the carboxyl in the SSA [16].

The dimensional analysis of the $\mathrm{Fe}_{3} \mathrm{O}_{4}$-SSA synthesized nanoparticles indicates good dispersion stability, by the DLS technique, using the Zetasizer Nano ZS (Malvern Instruments, Malvern, UK). According to the DLS results, the $\mathrm{Fe}_{3} \mathrm{O}_{4}$-SSA nanoparticles present an average hydrodynamic diameter of $50.55 \mathrm{~nm}$, good uniformity proved by the obtained polydispersity index value of 0.187 , and very good dispersion stability according to a zeta potential of $+45.3 \mathrm{mV}$ (Figure 3).

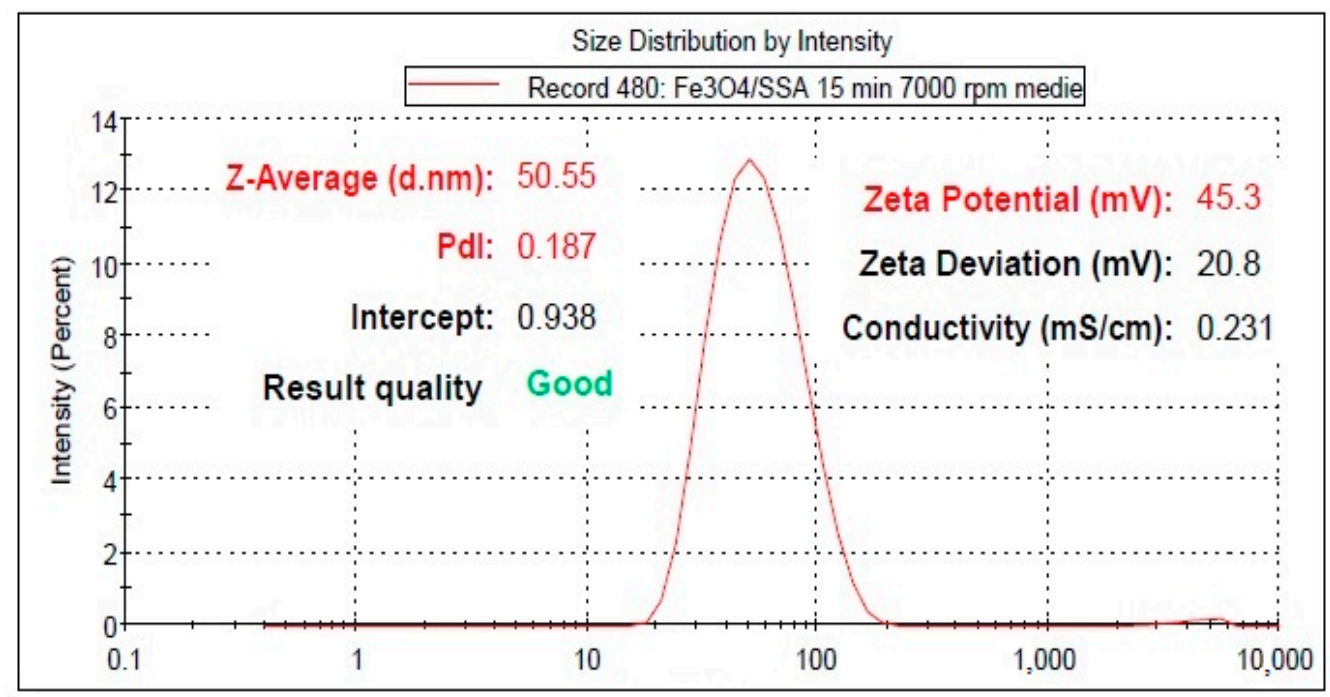

Figure 3. The results of the dynamic light scattering (DLS) analysis for the $\mathrm{Fe}_{3} \mathrm{O}_{4}-\mathrm{SSA}$ synthesized nanoparticles indicate good dispersion stability.

The TEM results indicate an average size of $20 \mathrm{~nm}$ of the internal core of the $\mathrm{Fe}_{3} \mathrm{O}_{4}-\mathrm{SSA}$ aggregate. The organic external shell was destroyed or diminished at higher beam energies [22], but specific techniques were used in order to highlight the SSA shell (Figure 4a). 


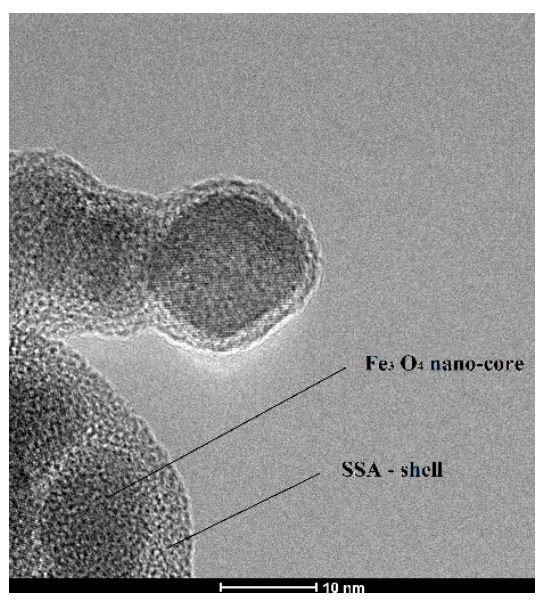

(a)

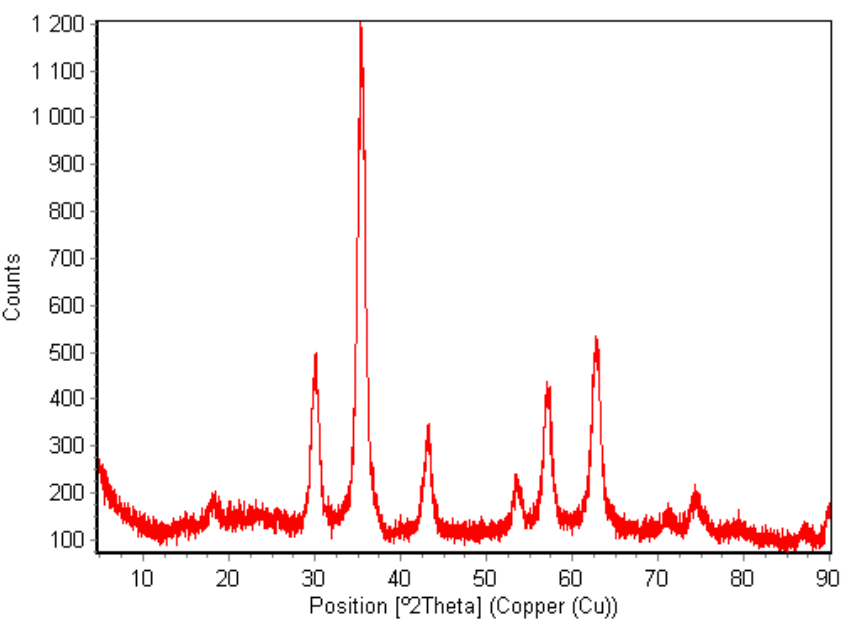

(b)

Figure 4. (a) The transmission electron microscopy (TEM) image of the synthesized $\mathrm{Fe}_{3} \mathrm{O}_{4}$ nanoparticles, to which the SSA molecules were attached as external shells; (b) X-ray diffraction (XRD) pattern of the nanofilm of the $\mathrm{Fe}_{3} \mathrm{O}_{4}$-SSA nanoparticles deposed by dip-coating.

The X-ray diffraction (XRD) pattern shows the presence of peaks at the $2 \theta$ values of $18.27^{\circ}, 30.18^{\circ}$, $35.42^{\circ}, 37.13^{\circ}, 43.22^{\circ}, 53.62^{\circ}, 57.18^{\circ}$, and 62.85 , corresponding to the (110), (220), (311), (222), (400), (422), (511), and (440) planes; crystallographic orientation is characteristic of the cubic spinel structure of $\mathrm{Fe}_{3} \mathrm{O}_{4}$ magnetic nanoparticles (Figure $4 \mathrm{~b}$ ).

\section{Experimental Results and Discussion of the OTFT Demonstrator}

First, we present the constructed organic TFT (OTFT) as the demonstrator, which was prepared on an ITO-coated glass substrate, purchased from Bruker Daltonics (Bremen, Germany). The next organic layers were deposited by dip-coating, which is a beneficial method that was recently used for metal-organic frameworks (MOFs) [6].

Polystyrene, approximately $200 \mathrm{~nm}$ thick, was deposited onto the ITO face by the dip-coating method at a $70 \mathrm{~mm} / \mathrm{min}$ extraction rate. The upper $\mathrm{Fe}_{3} \mathrm{O}_{4}-\mathrm{SSA}$ film, approximately $400 \mathrm{~nm}$ in thickness, was deposited onto the polystyrene film by dip-coating at a $90 \mathrm{~mm} / \mathrm{min}$ extraction rate. The organic film thicknesses were estimated by light reflection in the UV-visible spectrum, based on the dip-coating extraction speed determined in previous experiments [21,22].

The main challenge of film deposition is related to the correlation of the dispersibility of a ferrite core in different solvents. We started to test solvents of different polarities, such as water and ethanol, and we finished by selecting acetonitrile as the best candidate. The first issue we experienced was related to the adherence of the subsequent film $\left(\mathrm{Fe}_{3} \mathrm{O}_{4}-\mathrm{SSA}\right)$ to the previously-deposited film (i.e., polystyrene); here, the solution was to use the acetonitrile solvent. The second issue concerned the low dispersibility of the synthesized nanoparticles in the optimal solvents for subsequent deposition. This problem was solved by making specific modifications to the solvent-shell interaction one by one.

In this way, the transistor body, made from the $\mathrm{Fe}_{3} \mathrm{O}_{4}-\mathrm{SSA}$ film, was separated from the ITO conductor by polystyrene. The schematic structure of the demonstrator OTFT has direct source and drain contacts on the $\mathrm{Fe}_{3} \mathrm{O}_{4}-\mathrm{SSA}$ film, as well as a gate probe on the ITO film (Figure 5).

A similar characterization device is the pseudo-MOS transistor, which tests the electrical properties of an Si film on oxide [17]. For other organic semiconductors, similar OTFT test devices, which will be compared to our demonstrator, have similar arrangements for their sources, drains, and gates [23,24].

Our source, drain, and gate probes, made from Al, were mechanically-controlled by the Signatone S-725 micropositioner (Signatone Corporation, Gilroy, CA, USA) to ensure ohmic electrical contact [8]. A source-drain distance of $4000 \mu \mathrm{m}$ was the channel length of our OTFT (Figure 6). 


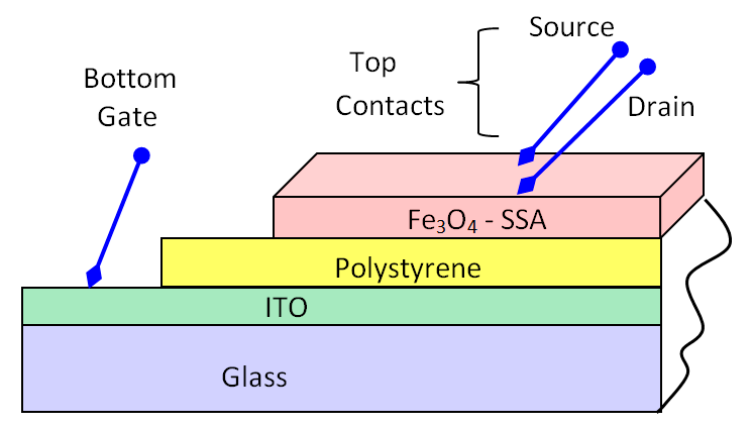

Figure 5. A schematic of the organic thin-film transistor (OTFT) structure, showing the successive layers and the three electrodes places: Gate in contact with the indium tin oxide (ITO), and the source and drain in contact with the $\mathrm{Fe}_{3} \mathrm{O}_{4}-\mathrm{SSA}$ film.

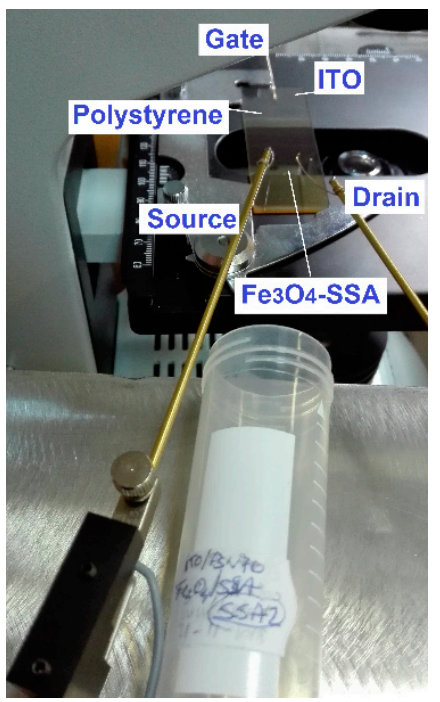

Figure 6. The experimental demonstrator: The source, drain in contact with te $\mathrm{Fe}_{3} \mathrm{O}_{4}-\mathrm{SSA}$ film (beige-colored), and gate connection to the ITO film. The colorless polystyrene film is longer than the $\mathrm{Fe}_{3} \mathrm{O}_{4}-\mathrm{SSA}$ film and is shorter than the ITO film, in agreement with Figure 5.

The demonstrator transistor was biased from a double-stabilized power supply HM8012 (Hameg Instruments $\mathrm{GmbH}$, Mainhausen, Germany). The drain currents were recorded by a Keithley6487 pico-ammeter (Keithley Instruments, Inc., Cleveland, OH, USA). The source was grounded, while the drain and gate electrodes were independently biased from HM8012. The source-drain resistances must measure tens of mega-ohms by a Hameg multimeter HM8012 to indicate that accidental penetration of the probes through the $\mathrm{Fe}_{3} \mathrm{O}_{4}$-SSA film has not occurred. Finally, the OTFT device was ready for testing.

First, the transfer characteristics $\mathrm{I}_{\mathrm{D}}-\mathrm{V}_{\mathrm{GS}}$ were measured for two $\mathrm{V}_{\mathrm{DS}}$ values, increasing the positive $\mathrm{V}_{\mathrm{GS}}$ voltage (Figure 7). The transfer characteristics are represented both on a linear scale (Figure 7a), allowing the extraction of the threshold voltage, $\mathrm{V}_{\mathrm{T}}$, and a vertical logarithmic scale (Figure $7 \mathrm{~b}$ ), allowing the extraction of the $\mathrm{I}_{\mathrm{ON}} / \mathrm{I}_{\mathrm{OFF}}$ ratio and the sub-threshold slope (SS). The $\mathrm{I}_{\mathrm{ON}}$ and $\mathrm{I}_{\mathrm{OFF}}$ currents are usually the maximum and minimum drain currents from the logarithmic scale. The main feature of a field-effect transistor was fulfilled: The drain current varied with the gate voltage (Figure 7a). Similar-shaped transfer characteristics to other OTFTs with a p-type pentacene [23] or an n-type organic [24] film are also visible in Figure 7a,b. We selected these two transistors [23,24] for comparison for a few reasons: (i) Pentacene is a reference material for organic transistors, such as Si for inorganic devices; (ii) pentacene usually presents p-type conduction $[7,23,25]$, but under special conditions, pentacene offers n-type conduction $[8,26]$; (iii) we compared the transfer characteristics of our test OTFT 
with those of the p-type pentacene OTFT-obviously, the chosen $I_{D}-V_{G S}$ points of $p$-type pentacene from [23] were inserted on the axis in Figure 7, considering $V_{\mathrm{GS}}=\left|\mathrm{V}_{\mathrm{GS}}\right|$; (iv) for further comparisons, we considered BASF material (BASF is a code of a perylene derivative used as an n-type film in [24]) in Figure 7, because it is an n-type material and it is a more recent development.

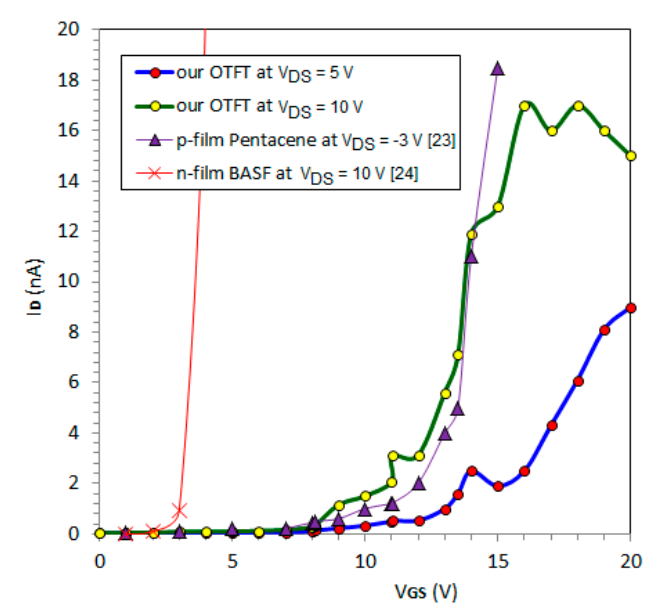

(a)

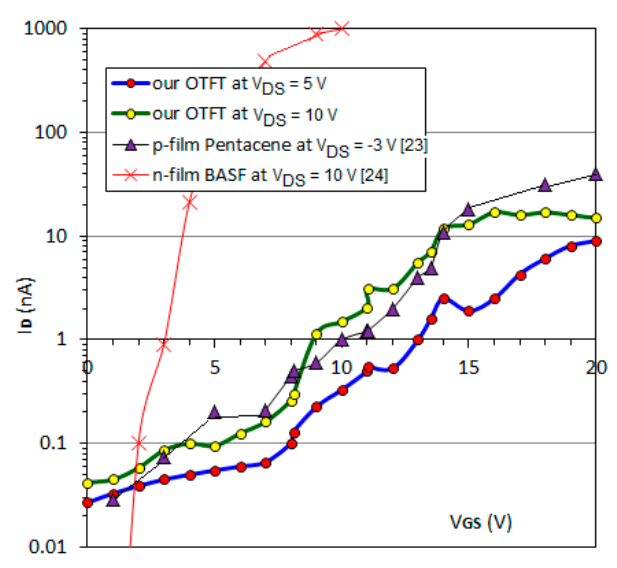

(b)

Figure 7. The recorded $\mathrm{I}_{\mathrm{D}}-\mathrm{V}_{\mathrm{GS}}$ curves: (a) Linear scale on both axes; (b) log scale on the vertical axis, as well as the chosen experimental points from the literature $[23,24]$.

The classical OTFT with p-type pentacene and an $\mathrm{MoO}_{3}$ insertion [23] provides the best fit of the modulus of the current with our measured current. A few parameters were close in value in the modulus: A threshold voltage $\left(\mathrm{V}_{\mathrm{T}}\right)$ of $5 \mathrm{~V}$, conventionally extracted as $\mathrm{V}_{\mathrm{T}}=\mathrm{V}_{\mathrm{GS}} \mid \mathrm{I}_{\mathrm{D}}=1 \%$. $\mathrm{I}_{\mathrm{D} \text {,max }}$; a conduction current $\left(\mathrm{I}_{\mathrm{ON}}\right.$ ) of $16 \mathrm{nA}$ (Figure $7 \mathrm{a}$ ); an $\mathrm{I}_{\mathrm{ON}} / \mathrm{I}_{\mathrm{OFF}}$ ratio of 500 and a slope (SS) of $5 \mathrm{~V} / \mathrm{dec}$ (Figure $7 \mathrm{~b}$ ). These values are inferior to those of another OTFT with an n-type organic film [24], presenting a slope (SS) of approximately $600 \mathrm{mV} / \mathrm{dec}$, a lower threshold voltage $\left(\mathrm{V}_{\mathrm{T}}\right)$ of $3.1 \mathrm{~V}$, a higher conduction current $\left(\mathrm{I}_{\mathrm{ON}}\right)$ of $1 \mu \mathrm{A}$, and a higher $\mathrm{I}_{\mathrm{ON}} / \mathrm{I}_{\mathrm{OFF}}$ ratio of $10^{5}$ (Figure $7 \mathrm{~b}$ ). The measured parameters from Figure 7 demonstrate an n-type OTFT with the accumulation channel at $\mathrm{V}_{\mathrm{GS}}>0$. The gate current of the proposed OTFT remained under the detection limit of the pico-ammeter for all tests, indicating that the actual OTFTs did not suffer from gate tunneling or probe penetration.

The output characteristics of our OTFT, $\mathrm{I}_{\mathrm{D}}-\mathrm{V}_{\mathrm{DS}}$, were measured for different $\mathrm{V}_{\mathrm{GS}}$ values (Figure 8). For comparison, the output characteristics of another n-type OTFT made from pentacene and contacted by $\mathrm{Al}$ source and drain electrodes [26], measured under special illumination conditions by other authors, are included in Figure 8.

Figure 8 reveals an approximate saturation voltage, $\mathrm{V}_{\mathrm{dsat}}$, of $+15 \mathrm{~V}$ for our OTFT and of $+10 \mathrm{~V}$ for the n-type OTFT made from pentacene. However, our OTFT achieved better performance in saturation: Higher saturated drain currents acted upon by much lower gate voltages (i.e., $\mathrm{V}_{\mathrm{G}}=10 \mathrm{~V}$ and $\mathrm{I}_{\text {Dsat }}=17 \mathrm{nA}$ ) than the n-type OTFT from [26] (i.e., $\mathrm{V}_{\mathrm{G}}=80 \mathrm{~V}$ and $\mathrm{I}_{\text {Dsat }}=5 \mathrm{nA}$ ). In our OTFT, the mobility of the carriers under saturation can be estimated by the following simple model [27]:

$$
\mathrm{I}_{\mathrm{D}, \mathrm{sat}}=\frac{\mathrm{W}}{2 \mathrm{~L}} \cdot \mu_{\mathrm{n}, \mathrm{sat}} \cdot \mathrm{C}_{\mathrm{PS}}\left(\mathrm{V}_{\mathrm{G}}-\mathrm{V}_{\mathrm{T}}\right)^{2}
$$

where $\mathrm{W}$ is the channel depth given by the probe's diameter $(500 \mu \mathrm{m}), \mathrm{L}$ is the channel length given by the distance between the source and drain probes $(2 \mathrm{~mm}), \mathrm{I}_{\text {Dsat }}$ is the current from the saturation region $\left(\sim 17 \mathrm{nA}\right.$ for $\mathrm{V}_{\mathrm{G}}=10 \mathrm{~V}$ in Figure 8$), \mathrm{C}_{\mathrm{PS}}$ is the specific capacity of the polystyrene layer $\left(11 \mathrm{~F} / \mathrm{cm}^{2}\right), \mathrm{V}_{\mathrm{G}}$ is the gate voltage $(10 \mathrm{~V}), \mathrm{V}_{\mathrm{T}}$ is the threshold voltage $(5 \mathrm{~V})$, and $\mu_{\mathrm{n}, \mathrm{sat}}$ is the electrons' mobility when the OTFT works under saturation. 


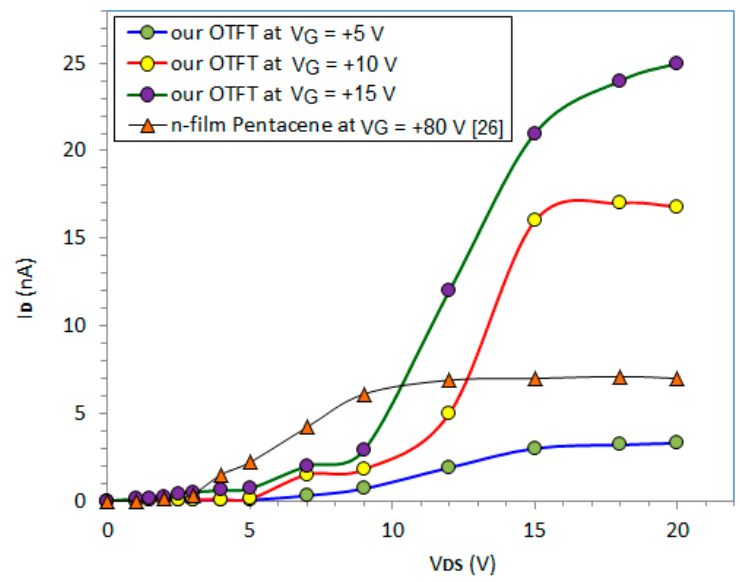

Figure 8. The output characteristics, $\mathrm{I}_{\mathrm{D}}-\mathrm{V}_{\mathrm{DS}}$, of our OTFT and those of an experimental n-type OTFT made from pentacene [26].

Equation (1) provides the value, $\mu_{\mathrm{n}, \mathrm{sat}}=0.45 \mathrm{~cm}^{2} / \mathrm{Vs}$ for the carriers mobility in our OTFT at $V_{G}=10 \mathrm{~V}$ and $V_{D S}>V_{d s a t}$. This value is superior than $\mu_{n, s a t}=0.054 \mathrm{~cm}^{2} / \mathrm{Vs}$, in the $\mathrm{n}$-film OTFT with pentacene, using the same model (1) and constructive data from [26].

\section{Discussions about the $\mathrm{n}$-Type Characteristics and the Low Toxicity of the $\mathrm{Fe}_{3} \mathrm{O}_{4}-\mathrm{SSA}$ Film}

In this section, the n-type characteristics of the $\mathrm{Fe}_{3} \mathrm{O}_{4}-\mathrm{SSA}$ compound are firstly discussed as the electron donor. Some specific conduction mechanisms through the SSA molecules from the external shells may arise. For this purpose, an SSA molecule was simulated by HyperChem molecular modeling software, indicating the following electric charge distribution (Figure 9).

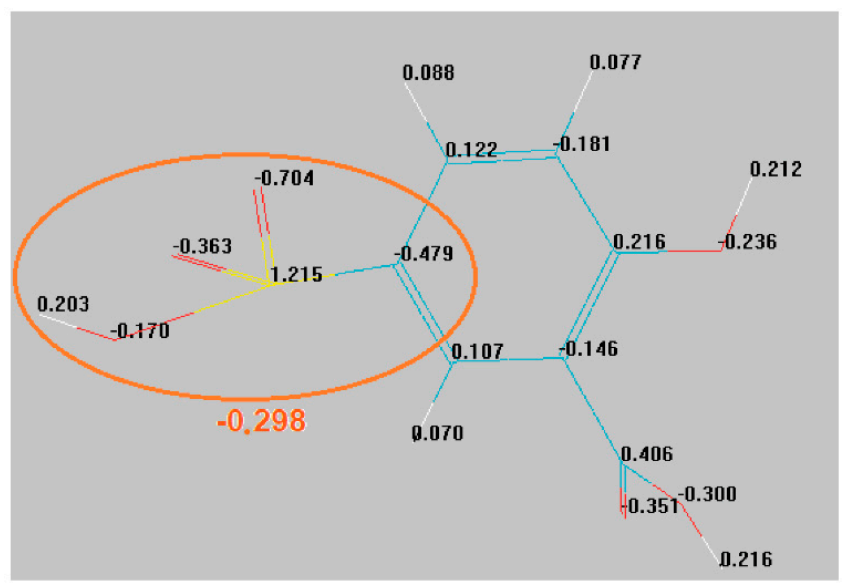

Figure 9. The simulation results of the electrical charge distribution inside the SSA molecule.

Inside the SSA molecule, the local electronic charge density, expressed by a normalized value at the elementary charge, was computed for each atom. The neutrality condition was fulfilled, because the global electrical charge of the SSA molecule was $+2.932-2.93 \cong 0$. However, the sulphonate group, $\mathrm{SO}_{3} \mathrm{H}$, possessed a net negative electronic charge density of -0.298 (Figure 9). This augments the argument to consider the SSA molecule an electron donor, subsequently offering the n-type behavior of the $\mathrm{Fe}_{3} \mathrm{O}_{4}-\mathrm{SSA}$ film. On the other hand, the $\mathrm{Fe}_{3} \mathrm{O}_{4}$ film or magnetite was indexed as a semiconductor with a Fermi energy of $3.64 \mathrm{eV}$ and band gap energy of $2.2 \mathrm{eV}$ [28]. Hence, the $\mathrm{Fe}_{3} \mathrm{O}_{4}$ core-shell substrate plays a significant role as a matrix for an intrinsic semiconductor. 
The second discussion concerns the low toxicity of the $\mathrm{Fe}_{3} \mathrm{O}_{4}-\mathrm{SSA}$ compound and its precursors during the technological flow. Ferrite has a low toxicity and by degradation, it can generate $\mathrm{Fe}^{+}$, $\mathrm{O}^{-}$ions, usually encountered in the human body and the environment.

A quantitative parameter for the evaluation of toxicity is the lethal dose, defined as a given quantity for the studied toxic substance that is administered per kilogram of the body weight of rats, at which a given percentage of the treated test animals die. The median lethal dose, denoted $\mathrm{LD}_{50}$, corresponds to a mortality of 50\% from the tested animals after inoculation with the substance [29]. Previously, various studies were performed to evaluate the toxicity of SSA [30]. For rats, the $\mathrm{LD}_{50}$ for SSA was established at $700 \mathrm{mg} / \mathrm{kg}$ [29]. This value indicates much lower toxicity of SSA than that of PAHs, such benzo[k]fluoranthene $\left(\mathrm{LD}_{50}=14 \mu \mathrm{g} / \mathrm{kg}\right)$ or other PAHs with an $\mathrm{LD}_{50}$ below $90 \mu \mathrm{g} / \mathrm{kg}$ [31]. Even in recent studies, a high cytotoxicity of polyphenolic compounds has been revealed [32], while polyphenols are specifically used for organic semiconductors applied in flexible electronics [33]. On the other hand, the precursor of SSA is salicylic acid-a veritable green compound that acts as a plant hormone or vascular drug [22].

\section{Conclusions}

This paper focused on the green synthesis of functional OTFT structures at very low prices. As a result, we demonstrated that an organic transistor with an $\mathrm{Fe}_{3} \mathrm{O}_{4}-\mathrm{SSA}$ film is operational. Obviously, many functional parameters have to be further optimized in the coming years to surpass the performance of the current OTFTs.

Herein, we investigated $\mathrm{Fe}_{3} \mathrm{O}_{4}-\mathrm{SSA}$ material as a candidate for green organic transistors. For this purpose, the synthesis of the $\mathrm{Fe}_{3} \mathrm{O}_{4}-\mathrm{SSA}$ material was based on co-precipitation. The FT-IR spectra confirmed the existence of SSA, while the TEM imaging captured the $\mathrm{Fe}_{3} \mathrm{O}_{4}-\mathrm{SSA}$ aggregates. The $\mathrm{Fe}_{3} \mathrm{O}_{4}$-SSA nanoparticles had good dispersion stability according to a zeta potential of $+45.3 \mathrm{mV}$.

The point-contact OTFT transistor with an $\mathrm{Fe}_{3} \mathrm{O}_{4}$-SSA film presented an increasing drain current as the positive gate voltage increased, demonstrating the n-type character of the film. This was the main experimental argument for inducing an electron accumulation channel with a positive gate voltage. Compared to other OTFTs, our $\mathrm{Fe}_{3} \mathrm{O}_{4}$-SSA transistor presented a threshold voltage of approximately $5 \mathrm{~V}$ and an $\mathrm{I}_{\mathrm{ON}} / \mathrm{I}_{\mathrm{OFF}}$ ratio of 500 , close to the parameters of a classical pentacene OTFT.

Author Contributions: C.R. and D.M. conceived and designed the experiments; A.M. performed the experiments and tested FTIR; B.P. and B.S.V. analyzed DLS and TEM tests; C.R. contributed the electrical characterization/analysis tools; C.R. and A.M. wrote the paper. All authors have read and agreed to the published version of the manuscript.

Funding: This research was funded by the Romanian National Authority for Scientific Research and Innovation, CNCS/CCCDI UEFISCDI, project number PN-III-P4-ID-PCE-2016-0480, project code 4/2017-2019 (TFTNANOEL). The APC was funded by Author Voucher discount code (d7a149a004628b34) from MDPI.

Conflicts of Interest: The authors declare no conflict of interest.

Impact Statement: The precursors of pentacene are carcinogenic to manufacturers and are toxic to the environment. Internet searching returned no results in 2020 for "n-type non-toxic organic semiconductor" for OTFTs. Our in-situ characterization device with a "green" sulpho-salicylic acid $\mathrm{Fe}_{3} \mathrm{O}_{4}$ nanocore proved the functionality of the n-type transistor.

\section{References}

1. Zhou, H.; Qin, W.; Yu, Q.; Cheng, H.; Yu, X.; Wu, H. Transfer Printing and its Applications in Flexible Electronic Devices. Nanomaterials 2019, 9, 283. [CrossRef] [PubMed]

2. Crossley, L.; Attoye, B.; Vezza, V.; Blair, E.; Corrigan, D.K.; Hannah, S. Establishing a Field-Effect Transistor Sensor for the Detection of Mutations in the Tumour Protein 53 Gene (TP53)-An Electrochemical Optimisation Approach. Biosensors 2019, 9, 141. [CrossRef] [PubMed]

3. Ravariu, C. Special features of the nothing on insulator transistor simulated with diamond lateral islands. Rom. Rep. Phys. 2018, 70, 1-10. 
4. Ramasamy, M.S.; Ryu, K.Y.; Lim, J.W.; Bibi, A.; Kwon, H.; Lee, J.-E.; Kim, D.H.; Kim, K. Solution-Processed PEDOT:PSS/MoS 2 Nanocomposites as Efficient Hole-Transporting Layers for Organic Solar Cells. Nanomaterials 2019, 9, 1328. [CrossRef] [PubMed]

5. Agarwal, R.; Agarwal, A.K.; Mazhari, B. Estimation of carrier mobility at organic semiconductor/insulator interface using an asymmetric capacitive test structure. AIP Adv. 2016, 6, 045017. [CrossRef]

6. Chaudhari, A.K.; Souza, B.E.; Tana, J.-C. Electrochromic thin films of Zn-based MOF-74 nanocrystals facilely grown on flexible conducting substrates at room temperature featured. APL Mater. 2019, 7, 081101. [CrossRef]

7. Fan, C.-L.; Shang, M.-C.; Wang, S.-J.; Hsia, M.-Y.; Lee, W.-D.; Huang, B.-R. Investigation of Rapid Low-Power Microwave-Induction Heating Scheme on the Cross-Linking Process of the Poly(4-vinylphenol) for the Gate Insulator of Pentacene-Based Thin-Film Transistors. Materials 2017, 10, 742. [CrossRef]

8. Tsai, T.-D.; Chang, J.-W.; Wang, C.-G.; Lin, M.-W.; Guo, T.-F.; Wen, T.-C.; Chang, J.-H.; Wu, C.-I. The origins in the transformation of ambipolar to n-type pentacene-based organic field-effect transistors. Org. Electron. 2014, 15, 1759-1766. [CrossRef]

9. Das, D.N.; Panda, P.K.; Naik, P.P.; Mukhopadhyay, S.; Sinha, N.; Bhutia, S.K. Phytotherapeutic approach: A new hope for polycyclic aromatic hydrocarbons induced cellular disorders, autophagic and apoptotic cell death. Toxicol. Mech. Methods 2017, 27, 1-17. [CrossRef]

10. Burke, D.J.; Lipomi, D.J. Green chemistry for organic solar cells. Energy Environ. Sci. 2013, 6, 2053. [CrossRef]

11. Gidron, O.; Dadvand, A.; Sheynin, Y.; Bendikov, M.; Perepichka, D.F. Towards "green" electronic materials. $\alpha$-Oligofurans as semiconductors. Chem. Commun. 2011, 47, 1976-1978. [CrossRef] [PubMed]

12. Komoda, T.; Sasabe, H.; Kido, J. Current Status of OLED Material and Process Technologies for Display and Lighting. In Proceedings of the 2018 25th International Workshop on Active-Matrix Flatpanel Displays and Devices (AM-FPD), Kyoto, Japan, 3-4 September 2018.

13. Wang, Y.; Tatsumi, H.; Otsuka, R.; Mori, T.; Michinobu, T. Highly-stable, green-solvent-processable organic thin-film transistors: Angular- vs. linear-shaped carbazoledioxazine derivatives. J. Mater. Chem. C 2018, 6, 5865-5876. [CrossRef]

14. Ravariu, C.; Mihalcscu, D.E.; Istrati, D.; Stanca, M. From Pentacene Thin Film Transistor to Nanostructured Materials Synthesis for Green Organic-TFT. In Proceedings of the 2018 International Semiconductor Conference (CAS), Sinaia, Romania, 10-12 October 2018.

15. Khanra, S.; Abdullah-Al Mamun, M.; Ferreira, F.F.; Ghosh, K.; Guha, S. Functionalized Self-Assembled Peptide Nanotubes with Cobalt Ferrite Nanoparticles for Applications in Organic Electronics. ACS Appl. Nano Mater. 2018, 1, 1175-1187. [CrossRef]

16. Wang, W.; Tang, B.; Wu, S.; Gao, Z.; Ju, B.; Teng, X.; Zhang, S. Controllable 5-sulfosalicylic acid assisted solvothermal synthesis of monodispersed superparamagnetic $\mathrm{Fe}_{3} \mathrm{O}_{4}$ nanoclusters with tunable size. J. Magn . Magn. Mater. 2017, 423, 111-117. [CrossRef]

17. Cristoloveanu, S.; Williams, S. Point-contact pseudo-MOSFET for in-situ characterization of as-grown silicon-on-insulator wafers. IEEE Electron Device Lett. 1992, 13, 102-104. [CrossRef]

18. Ravariu, C. Residual doping concentration estimation in a separation by IMplanted OXygen film using current measurements. IET Sci. Meas. Technol. 2013, 7, 1-6. [CrossRef]

19. Benea, L.; Bawedin, M.; Cristoloveanu, S.; Ionica, I.; Banu, M.; Simion, M.; Kusko, M.; Delacour, C. ४-MOSFET Configuration for DNA Detection. In Proceedings of the 2018 International Semiconductor Conference (CAS), Sinaia, Romania, 4-7 October 2018.

20. Jamasb, S. Continuous Monitoring of $\mathrm{pH}$ and Blood Gases Using Ion-Sensitive and Gas-Sensitive Field Effect Transistors Operating in the Amperometric Mode in Presence of Drift. Biosensors 2019, 9, 44. [CrossRef]

21. Morosan, A.; Mihaiescu, D.E.; Istrati, D.; Voicu, G.; Fudulu, A.; Stan, R. Polar shell magnetic nanostructured systems for heterogeneous nanophase reactions. UPB Sci. Bull. Ser. B 2018, 80, 53-64.

22. Mihaiescu, D.E.; Buteică, A.S.; Neamţu, J.; Istrati, D.; Mîndrilă, I. $\mathrm{Fe}_{3} \mathrm{O}_{4} /$ Salicylic acid nanoparticles behavior on chick CAM vasculature. J. Nanoparticle Res. 2013, 15, 1857. [CrossRef]

23. Wang, W.; Han, J.; Ying, J.; Xie, W. $\mathrm{MoO}_{3}$ Modification Layer to Enhance Performance of Pentacene-OTFTs With Various Low-Cost Metals as Source/Drain Electrodes. IEEE Trans. Electron Devices 2014, 61, 3507-3512. [CrossRef]

24. Uno, M.; Isahaya, N.; Cha, B.-S.; Omori, M.; Yamamura, A.; Matsui, H.; Kudo, M.; Tanaka, Y.; Kanaoka, Y.; Ito, M.; et al. High-Yield, Highly Uniform Solution-Processed Organic Transistors Integrated into Flexible Organic Circuits. Adv. Electron. Mater. 2017, 3, 1600410. [CrossRef] 
25. Völkel, A.R.; Street, R.A.; Knipp, D. Carrier transport and density of state distributions in pentacene transistors. Phys. Rev. B 2002, 66, 195336. [CrossRef]

26. Tsai, T.-D.; Huang, C.-Y.; Lin, H.-M.; Guo, T.-F.; Wen, T.-C. Switch the n-type to ambipolar transfer characteristics by illumination in n-type pentacene-based organic field-effect transistors. Org. Electron. 2014, 15, 3805-3810. [CrossRef]

27. Mittal, P.; Kumar, B.; Negi, Y.S.; Kaushik, B.K.; Singh, R.K. Channel length variation effect on performance parameters of organic field effect transistors. Microelectron. J. 2012, 43, 985-994. [CrossRef]

28. Wu, W.; Jiang, C.Z.; Roy, V.A.L. Recent progress in magnetic iron oxide-semiconductor composite nanomaterials as promising photocatalysts. Nanoscale 2015, 7, 38-58. [CrossRef]

29. Parra, A.L.; Yhebra, R.S.P.; Sardiñas, I.G.; Buela, L.I. Comparative study of the assay of and the estimate of the medium lethal dose (LD50 value) in mice, to determine oral acute toxicity of plant extracts. Phytomedicine 2001, 8, 395-400.

30. Sugai, S.; Hirai, A.; Mizuhashi, F.; Murata, K.; Kitagaki, T.; Ito, R. Toxicological evaluation of 5-sulfosalicylic acid. J. Med. Soc. Toho Univ. 1987, 34, 241-251.

31. Brunström, B.; Broman, D.; Näf, C. Toxicity and EROD-inducing potency of 24 polycyclic aromatic hydrocarbons (PAHs) in chick embryos. Arch. Toxicol. 1991, 65, 485-489. [CrossRef]

32. Cojocaru-Toma, M.; Ancuceanu, R.; Dinu, M.; Ciobanu, N.; Ciobanu, C.; Cotelea, T.; Jian, M.; Cobzac, V.; Nacu, V.; Toma, M.-M. Viability and cytotoxicity evaluation on isolated hepatocytes of some species rich in polyphenolic compounds. Adv. Nano-Bio-Mater. Devices 2020, 4, 580-585.

33. Jeong, J.; Essafi, M.; Lee, C.; Haoues, M.; Diouani, M.F.; Kim, H.; Kim, Y. Ultrasensitive detection of hazardous reactive oxygen species using flexible organic transistors with polyphenol-embedded conjugated polymer sensing layers. J. Hazard. Mater. 2018, 355, 17-24. [CrossRef]

(C) 2020 by the authors. Licensee MDPI, Basel, Switzerland. This article is an open access article distributed under the terms and conditions of the Creative Commons Attribution (CC BY) license (http://creativecommons.org/licenses/by/4.0/). 